\section{Revista Brasileira de Administração Científica}

Brazilian Journal of Scientific Administration

Abr a Jun $2021-v .12-$ n.2

\title{
Administração de materiais e ressuprimento: proposição de plano para uma distribuidora de materiais odonto-médico-hospitalares
}

A maior velocidade em satisfazer as necessidades e desejos dos consumidores fazem com que um bom gerenciamento de estoques seja essencial para alcança vantagem competitiva. A gestão de materiais é importante para a boa performance organizacional, pois permite a utilização mais eficiente dos recursos cada vez mais escassos. O objetivo do presente estudo é analisar e propor um plano de gerenciamento de estoques em uma empresa de fornecimento de materiais odontomédico-hospitalares na cidade de Vitória da Conquista/BA. Foi realizado um levantamento dos produtos adquiridos e custos administrativos/operacionais, entre junho de 2020 e dezembro de 2020. Ainda assim, houve a realização de entrevista semiestruturada com o gestor. Como resultado, foi constatado que a empresa realizava a gestão dos estoques com base no senso comum e houve compras equivocadas, falta e excesso de materiais. Produtos odonto-médico-hospitalares possuem alto custo de aquisição e manutenção. Estoques elevados como forma de diminuir o risco de falta de materiais foi nocivo para a organização. A principal contribuição deste estudo é voltada para a área gerencial com implicações práticas, a partir da aplicação de ferramentas de gestão de estoque como estoque mínimo, estoque máximo, lote econômico de compra, ponto de pedido e curva ABC. Tais ferramentas auxiliam na minimização de riscos operacionais.

\section{Materials administration and resuplement: plan proposition for a distributor of materials odonto-medical-hospitals}

\begin{abstract}
The increased speed in meeting the needs and desires of consumers makes good inventory management essential to achieve competitive advantage. Material management is important for good organizational performance, as it allows more efficient use of increasingly scarce resources. The objective of the present study is to analyze and propose an inventory management plan in a company that supplies dental-medical-hospital materials in the city of Vitória da Conquista/BA. A survey of purchased products and administrative/operational costs was carried out between June 2020 and December 2020. Even so, there was a semi-structured interview with the manager. As a result, it was found that the company carried out inventory management based on common sense and there were erroneous purchases, shortages and excess of materials. Dental-medical-hospital products have a high cost of acquisition and maintenance. High inventories as a way to reduce the risk of lack of materials was harmful to the organization. The main contribution of this study is focused on the management area with practical implications, based on the application of inventory management tools such as minimum stock, maximum stock, economic purchase lot, order point and $\mathrm{ABC}$ curve. Such tools help to minimize operational risks.
\end{abstract}

Keywords: Stock; Materials; Management; Control; Planning.

Topic: Planejamento, Estratégia e Competitividade

Reviewed anonymously in the process of blind peer.
Received: 07/04/2021

Approved: 04/06/2021
Anderson Dias Brito

Universidade Federal da Paraíba, Brasil http://lattes.cnpq.br/0674325468424953 http://orcid.org/0000-0003-0783-3884 andersonbrito.adm@gmail.com

Bruno de Souza Cruz (iD)

Fundação Getúlio Vargas, Brasil

http://lattes.cnpq.br/8782733465619724

http://orcid.org/0000-0002-2412-680X

brunosouzacruz1978@gmail.com

Matheus Almeida Piau Santana (iD)

Universidade Estadual do Sudoeste da Bahia, Brasil

http://lattes.cnpq.br/2737579872773288

http://orcid.org/0000-0003-3261-7171

piau.matheus@gmail.com

\author{
Jucimar Casimiro de Andrade \\ Universidade Federal Rural de Pernambuco, Brasil \\ http://lattes.cnpq.br/6423122913125713 \\ http://orcid.org/0000-0001-5539-4498 \\ jucimarcandrade@gmail.com
}

Referencing this:

BRITO, A. D.; CRUZ, B. S.; SANTANA, M. A. P.; ANDRADE, J. C.. Administração de materiais e ressuprimento: proposição de plano para uma distribuidora de materiais odonto-médico-hospitalares. Revista Brasileira de Administração Científica, v.12, n.2, p.69-82, 2021. DOI: http://doi.org/10.6008/CBPC2179-684X.2021.002.0006 


\section{INTRODUÇÃO}

Com um mercado cada vez mais complexo e concorrencial, as empresas precisam melhorar a gestão de maneira constante. Diante das diversas funções organizações a função de produção e a de marketing dependem diretamente de uma gestão eficiente de materiais. Sem a gestão de ressuprimentos, não há material para produzir ou comercializar, e consequentemente, não há geração de riqueza. Nesse sentido, manter a atividade e obter retorno sobre o capital investido é um desafio constante para as empresas (CALACIO et al., 2020).

Diante dos inúmeros esforços que as organizações estão realizando para se destacar, a gestão de estoques está ganhando cada vez mais espaço. De acordo com Paoleschi (2014), "uma empresa deve cuidar da gestão de estoques como o principal fundamento de todo o seu planejamento, tanto estratégico, como operacional". Dessa forma, a gestão de materiais é um dos meios para que a organização possa se destacar em um cenário competitivo, através da eficiência e atendimento de excelência ao consumidor.

A gestão de materiais está intimamente relacionada à gestão de estoques. A gestão de materiais é a função responsável pelo planejamento e controle do fluxo de materiais (ARNOLD, 1999). Em relação aos estoques, são qualquer quantidade de materiais armazenados por um intervalo de tempo para suprir uma demanda futura (MOREIRA, 2012). Esses conceitos estão relacionados, em razão que não é suficiente à disposição dos materiais em estoques, é preciso um planejamento e controle eficiente para que não traga consequências para as organizações como, por exemplo, faltas, excessos e ruptura ou alterações forçadas dos planos mestres de produção.

Gerenciamento de estoque, por meio de ferramentas, permite controlar o volume de produtos armazenados, auxiliando na tomada de decisão de novas compras, organização e distribuição dos materiais (DANDARO et al., 2015). A agilidade em atender as necessidades e desejos dos consumidores fazem com que um bom gerenciamento de estoques seja essencial para alcançar vantagem competitiva. Logo, se torna válido analisar o impacto das ferramentas de gestão de estoques, pois é essencial para se encontrar um limiar entre um alto nível de serviço e o volume de materiais adequado.

A empresa analisada está situada na cidade de Vitória da Conquista, na Bahia, e atua no segmento de produto odonto-médicos-hospitalares. A empresa foi adquirida por três sócios e além de herdar um estoque volumoso de materiais, por vezes sem uso, a gestão dos materiais era baseada no senso comum. Tal gestão trouxe impactos negativos para a organização, afetando o seu setor operacional e financeiro. Assim sendo, o objetivo do presente estudo é analisar e propor um plano de gerenciamento de estoques em uma empresa de fornecimento de materiais odonto-médico-hospitalares.

\section{REVISÃO TEÓRICA}

\section{Gestão de Materiais}

A gestão de materiais é fundamental para o bom desempenho organizacional, uma vez que permite a utilização mais eficiente dos recursos, evitando excessos, faltas e obsolescência. Essa gestão representa 
uma questão de interesse nas operações, uma vez que pode reduzir ou promover a flexibilidade do ambiente produtivo, impactar nos resultados da organização (KLIPPEL et al., 2007) e obter respostas mais rápidas e efetivas.

Em uma cadeia de suprimentos, a gestão de materiais é essencial, pois é responsável para que os produtos estejam na quantidade ideal para atender a demanda. Essa gestão de materiais está presente desde a matéria prima até ao consumidor final, mas é importante ressaltar que em um cenário de preocupação ambiental, o consumidor deixa de ser o elo final da cadeia e passa a ser o intermediário.

A mudança na estrutura da cadeia de suprimentos pode ser constatada com o conceito de logística reversa, à qual é o retorno dos bens do pós-consumo ao ciclo produtivo, por meio dos canais de distribuição reversos (LEITE, 2005). Quanto menos descartes inadequados, melhor para a preservação do meio ambiente e para a imagem corporativa e na relação de custos da organização. Assim, é percebido o quanto a gestão de materiais é importante desde a matéria primária até o retorno dos resíduos para reciclagem ou reaproveitamento.

Por muito tempo, ter um setor responsável pela gestão dos materiais foi visto como desperdício de recursos, mas com o mercado cada vez mais competitivo, as organizações precisam se adequar à nova realidade. Essa adoção de um setor responsável é o melhor caminho para que as empresas consigam reduzir seus custos e potencializar o desempenho dos processos e recursos, visando a maior satisfação do consumidor.

A informação da demanda passa de organizações em organizações até atingir o fornecedor de matéria-prima (OLIVEIRA et al., 2004). Essa troca de informação também ocorre em sentido oposto e a variável que pode mais refletir a informação, é o preço. O preço é quem vai ditar os diferentes níveis de oferta e demanda. Para as pequenas variações na relação de oferta e demanda, os níveis de estoques devem ser flexíveis para continuar com as operações mercadológicas sem prejuízos econômicos ou financeiros para as organizações.

O aumento do desempenho de uma cadeia de suprimentos pode vir pela redefinição dos processos físicos ou dos processos de decisões (OLIVEIRA et al., 2004). Essas redefinições ocorrem pelo alinhamento dos objetivos do negócio, a partir do reconhecimento de tendências e padrões ao longo do tempo, ao invés de soluções pontuais. Logo, os parceiros podem negociar nível de serviço, leadtime de reposição, preços, contrato de suprimento e lotes mínimos.

\section{Estoque de Segurança}

Estoque de segurança, estoque reserva, safety stock, buffer stock possuem a mesma denominação para uma quantidade de materiais que serão utilizados caso haja uma demanda maior que a prevista ou atraso na entrega de um pedido. Além de cobrir as variações estocásticas da demanda e do tempo de ressuprimento, o estoque de segurança também tem seu papel quando há falha no ressuprimento, no transporte, na comunicação, na produção, na previsão da demanda, entre outros (WILD, 2002; ROSA et al., 2010). 
Em suma, o estoque de segurança é a quantidade de materiais que visa cobrir imprevistos ou erros no planejamento. Considerando que quando se lida com processos, é possível existir falhas internas como, não fazer o pedido no momento adequado e não solicitar a quantidade necessária. Do mesmo modo, pode existir falhas externas, mais precisamente com fornecedores, como atraso na confecção do pedido e atraso na entrega do produto acabado por questões logísticas. Com isso, o estoque de segurança minimiza os riscos e impactos da falta de materiais, de modo a permitir que os processos produtivos funcionem sem interrupções (POZO, 2015) para determinado momento.

De acordo com Dias (2012), para calcular o estoque de segurança existem várias fórmulas, mas a mais simples é através da equação 1 :

$$
\text { Eseg }=\mathrm{C} \times \mathrm{K}
$$

Onde:

Eseg $=$ Estoque de segurança $\mathrm{C}=$ Consumo mensal (média)

$\mathrm{K}=$ Fator arbitrário de segurança para diminuir o risco de ruptura.

Na prática, é importante revisar a quantidade que será utilizada como estoque de segurança, pois em muitos casos, a demanda não é constante durante o ano. Trabalhar com média também traz alguns riscos como, por exemplo, além da presença de outliers , não captura completamente os efeitos da volatilidade da demanda. Além disso, é importante proporcionar giros de entrada e saída no estoque de segurança para que não ocorra riscos de obsolescência, quebras, furtos, dentre outros.

O estoque de segurança também traz impactos para a gestão de custos, pois não há necessidade de ter grandes volumes de materiais para atender uma demanda que antes era baseada no senso comum. Além disso, o armazenamento de qualquer material gera custos, sejam de capital, de pessoal, com edificação ou com manutenção (DIAS, 2012); com menos estoques, menor serão os custos de manutenção sem afetar a segurança proporcionada para atender a demanda.

\section{Lote Econômico de Compra}

A cadeia de abastecimento é uma das áreas que mais representa custos para as organizações. Comprar mais que o necessário pode além de impactar nos custos de armazenamento, fazer com que os recursos financeiros fiquem sem movimentação, sendo que poderia ser utilizado para outros fins, como por exemplo, investimentos ou até mesmo melhorar a liquidez da empresa.

Por outro lado, comprar grandes quantidades de material pode melhorar o relacionamento com os fornecedores, conseguir descontos expressivos, alcançar prazos de pagamento maiores e diminuir a probabilidade de faltar material. Logo, surge um tradeoff que mesmo apesar dos benefícios, é preciso pensar em um equilíbrio, pois em momentos de crise, muitas empresas estão com dificuldade de liquidez, precisam diminuir seus custos e precisam de recursos para honrar seus compromissos.

Uma alternativa para amenizar ou até mesmo solucionar esse tradeoff é a utilização do Lote Econômico de Compra - LEC. Para Oliveira et al. (2015) o LEC é a mensuração da quantidade ideal para a aquisição de materiais na reposição de estoque, em que os gastos (estocagem, movimentação interna e 
pedido) sejam os mínimos possíveis. Ainda assim, o LEC é uma ferramenta mais comum para verificar o quanto de material deve ser pedido, a partir do equilíbrio de vantagens e desvantagens do material em estoque (SLACK et al., 2018).

Os gastos com estocagem são todos os recursos necessários para que os materiais sejam armazenados como, galpões, funcionários e equipamentos de armazenagem dentro do estoque. Os gastos de movimentação, são os gastos relacionados aos transportes de materiais na empresa como, empilhadeiras e esteiras. Os gastos de pedido estão relacionados ao administrativo como, funcionários e computadores. Vale ressaltar que esses gatos dependem do tipo de produto a ser estocado, pois cada tipo material pode exigir mais ou menos recursos do que outros.

De acordo com Corrêa et al. (2007), o LEC pode será calculado através da equação disposta na figura 1.

$$
L_{E}=\sqrt{\frac{2 \times D A \times C_{f}}{C_{e}}}
$$

Figura 1: o Lote Econômico de Compra. Fonte: Corrêa et al. (2007).

Em que: $\mathrm{DA}=$ Demanda anual. $\mathrm{Cf}=$ Custo por pedido. $\mathrm{Ce}=$ Custo unitário anual de estocagem.

É importante tecer algumas críticas à ferramenta do LEC, uma vez que não fornece resultados precisos e sim estimativas, pois os consumos e os prazos de entrega têm volatilidade. $O$ custo de manter em estoque muitas vezes é baseado no preço do material, mas é possível que na prática, a manutenção seja mais cara do que o próprio item. Logo, é de suma importância analisar cuidadosamente os inputs das fórmulas com as devidas correções para oferecer estimativas mais próximas da realidade.

\section{Curva ABC}

A curva $A B C$ é um método idealizado pelo economista Vilfredo Pareto, em 1987, para discutir a distribuição de renda. Pareto observou que havia uma concentração de renda, em que nas mãos de $20 \%$ de determinada população havia a maior concentração de renda (80\%).Esse modelo foi incorporado para a área de produção, recebendo contribuições e sendo utilizado por diversas empresas que se preocupam com a gestão de estoque.

A curva $A B C$ é uma importante ferramenta para a composição de estoques e contribui para que a organização seja mais eficiente e eficaz na gestão de materiais. Essa ferramenta funciona da seguinte forma: "aos itens mais importantes, dá-se a denominação itens classe ' $A$ ', aos intermediários, itens classe ' $B$ ', e aos menos importantes, itens classe ' $C$ '” (PERES et al., 2020). Na prática, usa-se a classe ' $A$ ' para os $20 \%$ dos itens que precisam de maior atenção e monitoramento, devido a seu alto valor. A classe 'B' é composta pelos $30 \%$ dos itens que depois da classificação ' $A$ ' possuem maior valor, merecendo relativa importância. A classe ' $C$ ' representa o restante dos itens (50\%) com menor valor e são menos importantes para a organização.

Pozo (2015) descreve alguns passos para montar a curva ABC, sendo: (a) contabilidade a quantidade 
de itens que serão usados no modelo com os respectivos preços unitários e totais. (b) fazer uma tabela em ordem decrescente de faturamento. (c) relacionar o valor total de cada item pelo valor do somatório de todos os itens para descobrir a porcentagem. (d) dividir os itens em classes A, B e C de acordo com a porcentagem acumulada. Segundo Dias (2010), "a curva $A B C$ tem sido usada para a administração de estoques, para a definição de políticas, estabelecimento de prioridades para a programação da produção e uma série de outros problemas usuais na empresa". Ao final das etapas, a curva $A B C$ pode ser visualizada graficamente através da figura 2.

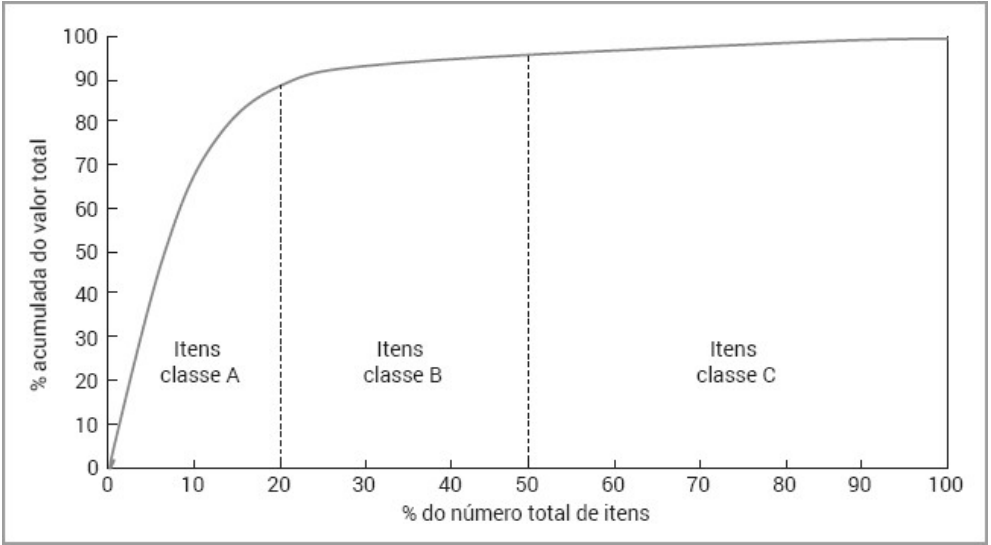

Figura 2: Curva ABC. Fonte: Slack et al. (2018).

Identificar a classificação dos produtos entre os mais e menos importantes pode auxiliar no entendimento dos recursos financeiros aplicados no estoque. A partir desse entendimento, pode-se realizar melhores análises e decisões que tornem a gestão do estoque mais eficiente. $O$ método da curva $A B C$ permite um controle seletivo do estoque, pois é necessário diferenciá-los dada suas particularidades em relação à importância para as organizações.

Vale ressaltar que o método $A B C$ é importante para a gestão dos estoques, mas é preciso considerar que cada material tem sua importância para a organização. Os classificados como ' $C$ ' são procurados por clientes e sua ausência fará com que os consumidores busquem pela concorrência e consequentemente haja diminuição no faturamento da empresa que não dispõe do material.

\section{METODOLOGIA}

O objetivo do presente estudo é analisar e propor um plano de gerenciamento de estoques em uma empresa de fornecimento de materiais odonto-médico-hospitalares, na cidade de Vitória da Conquista-BA. Para alcançar o objetivo, foi realizada uma análise das compras e vendas dos estoques e um levantamento de custos administrativos/operacionais que serviram de inputs para as ferramentas apresentadas na revisão de literatura. Por conseguinte, foi realizada uma entrevista semi estruturada com gestor para saber sobre o histórico da empresa, como era feita a gestão de estoques e como as ferramentas apresentadas neste estudo poderiam trazer impacto para a organização.

Esta pesquisa é descritiva, pois busca descrever fenômenos e características do ambiente e suas inter-relações, através da coleta e análise de dados. Para Gil (2017), as pesquisas descritivas têm como 
objetivo mostrar características da população ou fenômeno estudo, através do uso de técnicas para coleta de dados.

A proposição de planos foi utilizada como estratégia de pesquisa para buscar soluções dos problemas organizacionais. Além disso, esta pesquisa possui características quantitativas e qualitativas. Quantitativa, através do uso de indicadores e análise exploratória de dados em relação ao estoque e movimentação de materiais da empresa. Qualitativa através de realização de entrevista com o gestor para análise do discurso. A análise de dados quantitativos foi realizada à luz da revisão de literatura, através de equações para se calcular o estoque de segurança, ponto de pedido, lote econômico de compra e estoque máximo dos itens analisados

Este estudo coletou dados entre junho de 2020 e dezembro de 2020. Para garantir a coleta de dados confiáveis, foram utilizadas as notas fiscais de compra e venda dos materiais emitidas no período analisado. Para o leadtime médio, utilizou o registro de e-mails desde a solicitação do material até a sinalização do recebimento. Para o custo do pedido e armazenamento, foi solicitado dados da contabilidade da empresa, como conta de luz, água, aluguel, IPTU, internet, dentre outros. A partir da coleta de dados foi possível identificar erros nos processos e definir métodos de controle de acordo com as necessidades identificadas.

\section{Descrição da empresa}

A empresa analisada iniciou suas operações em 2009, no município de Porto Seguro - BA, oferecendo produtos odonto-médico hospitalares para hospitais da região. Ao final de 2018, a empresa foi comprada por três investidores, os quais decidiram migrar as operações para a cidade de Vitória da Conquista - BA. De acordo com o gestor, a escolha pela mudança de cidade foi em razão do interesse dos acionistas em tornar a empresa mais competitiva e com maior participação de mercado, em uma cidade mais populosa e referência em saúde, no âmbito do interior da Bahia e do Norte de Minas Gerais.

A empresa analisada atende duas grandes áreas do campo cirúrgico, sendo elas ortopedia e neurologia. Devido à complexidade dessas áreas, há inúmeros procedimentos que a empresa fornece diferentes tipos de material como, por exemplo, procedimentos de artrodese lombar, artrodese cervical, artroscopia, descompressão medular, exéreses de tumor, derivações ventriculares, clipagem de aneurisma, tratamento cirúrgicos para fraturas ósseas, próteses e órteses, dentre outros.

Com a aquisição da empresa, herdou-se um estoque volumoso de materiais de apoio, chamado de instrumental (pinças, afastadores, ruginas, impactadores, entre outros) e material de implante (próteses, hastes, parafusos, placas, entre outros). Após a compra da empresa, os investidores expandiram o mix de produtos, ao fornecer materiais descartáveis e bioativos, isto é, materiais que atuam no organismo com função de tratamento ou substituição.

Tanto os materiais que foram herdados, quanto os adquiridos, possuem características distintas de outros produtos, como por exemplo, seu alto custo de aquisição e manutenção, além de um alto custo de falta de estoque, pois se tratando da área cirúrgica, a ausência de um material em estoque resulta a não realização de uma cirurgia e a depender do grau de urgência/emergência, o paciente pode ir a óbito. 
Vale ressaltar que os procedimentos cirúrgicos frequentemente são reinventados e ajustados, conforme o surgimento de novas abordagens e técnicas. Esse processo de inovação faz com que exista a necessidade de atualizar o mix de produtos de maneira constante. Por outro lado, é preciso um maior cuidado com relação a gestão de estoques, pois com a inovação, alguns materiais de técnicas não atuais caem em desuso e há perda do valor investido, pois não há demanda para estes.

A empresa começou a ter um controle mais rigoroso na gestão de estoque por volta de junho de 2019, a partir da utilização de protocolos e planilhas de movimentação de materiais. A empresa também herdou um software de gestão integrado que possui algumas funções que poderiam auxiliar na gestão de estoque, porém, esse software possui algumas limitações, informações cadastradas de maneira errônea e não atende à necessidade da empresa, caso seja feito um controle mais acurado. Ao final de 2019 , foi iniciado o processo de implementação de um novo sistema para auxiliar na gestão de materiais, porém, até a data de realização do presente estudo, o sistema encontra-se em fase de testes.

\section{Fluxo operacional da empresa analisada}

Inicialmente, o comercial recebe uma solicitação de cotação de materiais a serem utilizados na cirurgia. Caso a cotação seja aprovada pelo cliente, a gerência operacional é informada para verificar se haverá necessidade de encaminhar mais material do que o solicitado, tendo em vista que pode ocorrer imprevistos durante a cirurgia. Após análise dos materiais solicitados pela gerência operacional, é encaminhada a relação de itens para o analista de estoque.

O analista irá no local de armazenamento, separa os materiais, lança as informações do material com referência, descrição, lote, quantidade e dados da cirurgia em uma planilha de controle de movimentação e preenche o protocolo de saída. O pessoal encarregado pelo transporte dos materiais confere a relação dos itens contida no protocolo e a quantidade a ser entregue. Ao chegar no setor responsável no hospital, há nova conferência e é coletado a assinatura do responsável pelo recebimento do material na unidade de saúde. Após a assinatura, esse protocolo retorna para a empresa e é arquivado até a realização do procedimento cirúrgico.

Quando o procedimento é realizado, o hospital deve preencher a folha de sala e encaminhar à empresa que forneceu os materiais. Essa folha consta a relação dos materiais que efetivamente foram utilizados na cirurgia com descrição, referência e lote, bem como dados da cirurgia, paciente, cirurgião, hospital, convênio, data, horário, dentre outras informações. $O$ analista de estoque recebe essa folha de sala, confere com o protocolo da empresa, sinaliza quais materiais não foram utilizados e que devem retornar a empresa.

O analista informa a relação dos materiais a serem retirados no hospital, e o encarregado entra em contato com o responsável pelo setor do hospital e confere se o material que não foi utilizado foi devidamente devolvido. Novamente, o analista confere o que foi utilizado com a folha de sala e o que foi devolvido pelo $\mathrm{p}$ hospital. O material é restituído para o estoque e as informações da planilha são ajustadas para não haver divergência do estoque realmente e da planilha. Por fim, a folha de sala é entregue ao 
faturamento que realiza o processamento após autorização do hospital ou convênio

\section{RESULTADOS E DISCUSSÃO}

Este estudo analisou 1115 tipos de itens que compõem o estoque da empresa. A quantidade bruta de materiais em estoque no dia 30 de dezembro de 2020 era de 6346 itens. Destes 1115 tipos de itens, apenas 178 apresentaram giros em 07 meses (média de giro em 1,11) e resultaram em um custo de material vendido em $\mathrm{R} \$ 174.691,10$ (cento e setenta e quatro mil e seiscentos e noventa e um reais e dez centavos).

Vale ressaltar que a maior parte do estoque foi herdada na aquisição da empresa, ou seja, a empresa já foi adquirida com estoque de 847 tipos de itens. Ao longo de sete meses, a empresa, ao prever uma demanda, adquiriu 268 novos tipos de itens, por um total de $\$ 400.093,38$ (quatrocentos mil e noventa e três reais e trinta e oito centavos). Ao comparar o valor do estoque comprado e o custo das mercadorias vendidas do estoque como um todo, percebe-se que o valor das compras representou mais que o dobro do que foi efetivamente vendido

Dos 268 tipos de itens comprados nos sete meses analisados, apenas 109 tiveram movimentação (média de 1,49 giros), sendo 59 níveis ' $A$ '; 25 níveis ' $B$ ' e 28 níveis ' $C$ '. Nesse sentido, percebe-se que a empresa não comercializa mais da metade dos produtos comprados e consequentemente, houve estagnação parcial do capital investido. A justificativa pela gerência foi um erro de estimativa de demanda, em que se acreditava que alguns produtos poderiam ser demandados por hospitais e cirurgiões, o que de fato não aconteceu.

Dos 847 itens do estoque que vieram com a empresa, apenas 69 apresentaram giro nos últimos 07 meses (média de 0,51), sendo 6 níveis ' $A$ ', 15 níveis ' $B$ ' e 48 níveis ' $C$ '. Como a empresa já foi adquirida com estoque, grande parte dos materiais estavam obsoletos e sua utilização foi substituída por novas tecnologias mais eficientes.

Foi calculado os custos para realizar os pedidos dos materiais odonto-médicos hospitalares e o custo de armazenagem desses materiais, sendo ambos mensais. Considerando que o Analista de Gestão de Estoque é responsável pela função de realizar o pedido e controlar o armazenamento, seu salário foi dividido por essas duas funções.

Quadro 1: Custo do pedido e custo de armazenamento da empresa.

\begin{tabular}{llrlr}
\hline Contas & \multicolumn{2}{l}{ Custo dos Pedidos } & \multicolumn{2}{l}{ Custo de Armazenamento } \\
\hline Salários + encargos & $\mathrm{R} \$$ & 986,63 & $\mathrm{R} \$$ & 986,63 \\
Despesas administrativas e suprimentos & $\mathrm{R} \$$ & 152,51 & $\mathrm{R} \$$ & 282,36 \\
Depreciação & $\mathrm{R} \$$ & 52,29 & $\mathrm{R} \$$ & 65,00 \\
Despesas Operacionais & $\mathrm{R} \$$ & 185,98 & $\mathrm{R} \$$ & 604,85 \\
\hline Total & $\mathbf{R} \$$ & $\mathbf{1 . 3 7 7 , 4 0}$ & $\mathbf{R} \$$ & $\mathbf{1 . 9 3 8 , 8 4}$ \\
\hline
\end{tabular}

A armazenagem desses materiais precisa seguir critérios de qualidade definidos pela legislação como, por exemplo, ser armazenado em local fechado, pouca luminosidade, temperatura reduzida, limpeza, dentre outros. Esses critérios para atender a legislação demandam recursos de espaço, tempo e dinheiro para que garanta a qualidade necessária para realizar as operações da empresa. Com isso, a empresa armazena atualmente 6346 unidades de materiais odonto-médicos hospitalares, perfazendo um custo unitário de 
armazenagem por produto de aproximadamente $\mathrm{R} \$ 0,31$ centavos por mês.

A empresa analisada realizou 12 pedidos em junho, 26 em julho, 25 em agosto, 21 em setembro, 20 em outubro, 28 em novembro e 15 em dezembro. A média simples e a mediana foram de 21 pedidos por mês, o que leva ao custo médio de cada pedido por $\$: 65,59$ reais. Ainda assim, foi constatado que houve reincidência de pedidos no mês com os mesmos fornecedores. De acordo com a pesquisa, foram realizados em média 1,5 pedidos mensalmente para cada fornecedor, sendo que já houve incidência de cinco pedidos com o mesmo fornecedor no mês. Esse fato leva ao aumento de trabalho dos funcionários, dos custos com os pedidos, os gastos com fretes e o aumento do risco de faltar produtos para atender cirurgias.

Para realização da curva $A B C$, foram utilizados apenas produtos que tiveram movimentação no período de junho a dezembro de 2019. Dentre os 47 produtos analisados, 20 foram classificados como categoria ' $A$ ', isto é, estes produtos são os que mais influenciam no faturamento da empresa. Classificados como categoria ' $B$ ', 12 produtos alcançaram esse patamar, ou seja, esses produtos influenciam de forma mediana o faturamento da empresa. Por fim, 15 produtos foram classificados como categoria ' $C$ ', em outras palavras, estes são os produtos que menos influenciam no faturamento da empresa.

Quadro 2: curva $A B C$ dos produtos analisados.

\begin{tabular}{|c|c|c|c|c|}
\hline Produto & Faturamento & \begin{tabular}{|l|}
$\begin{array}{l}\text { Participação } \\
\text { Faturamento }\end{array}$ \\
\end{tabular} & $\begin{array}{l}\text { Participação Acumulada } \\
\text { no Faturamento }\end{array}$ & $\begin{array}{l}\text { Classificação } \\
\text { ABC }\end{array}$ \\
\hline Parafuso Pedicular Poliaxial & $\mathrm{R} \$ \quad 142.578,28$ & $16,42 \%$ & $16,42 \%$ & $\mathrm{~A}$ \\
\hline Haste Longitudinal & $\mathrm{R} \$ \quad 108.784,66$ & $12,53 \%$ & $28,95 \%$ & A \\
\hline Válvula para Hidrocefalia & $53.500,92$ & $6,16 \%$ & $35,10 \%$ & A \\
\hline Hemostático & $41.872,43$ & $4,82 \%$ & $39,93 \%$ & A \\
\hline Parafuso Cortical Inox & $28.771,97$ & $3,31 \%$ & $43,24 \%$ & A \\
\hline Parafuso Cortical Titânio & $28.734,09$ & $3,31 \%$ & $46,55 \%$ & $A$ \\
\hline Contra parafuso com anel & $28.424,82$ & $3,27 \%$ & $49,82 \%$ & A \\
\hline Adesivo Cirúrgico & $24.720,19$ & $2,85 \%$ & $52,67 \%$ & A \\
\hline Placa para Cervical & $23.722,44$ & $2,73 \%$ & $55,40 \%$ & $A$ \\
\hline Placa Tubular & $22.897,37$ & $2,64 \%$ & $58,03 \%$ & A \\
\hline Membrana Sintética & $22.877,03$ & $2,63 \%$ & $60,67 \%$ & A \\
\hline Parafuso Monocortical & $22.039,24$ & $2,54 \%$ & $63,21 \%$ & A \\
\hline Cage Cervical & $20.969,47$ & $2,41 \%$ & $65,62 \%$ & A \\
\hline Hidroxiapatita & $20.241,63$ & $2,33 \%$ & $67,95 \%$ & A \\
\hline Broca Craniana & $19.870,00$ & $2,29 \%$ & $70,24 \%$ & A \\
\hline Compressa Neurocirúrgica & $18.191,59$ & $2,09 \%$ & $72,33 \%$ & A \\
\hline Parafuso de Bloqueio Inox & $16.418,58$ & $1,89 \%$ & $74,22 \%$ & A \\
\hline Campo Cirúrgico & $16.231,57$ & $1,87 \%$ & $76,09 \%$ & A \\
\hline Cânula para Artroscopia & $15.857,39$ & $1,83 \%$ & $77,92 \%$ & A \\
\hline Haste Proximal & $15.767,83$ & $1,82 \%$ & $79,73 \%$ & A \\
\hline Botão de fechamento de crânio & $14.600,37$ & $1,68 \%$ & $81,41 \%$ & $\mathrm{~B}$ \\
\hline Barra Tubular & $13.872,68$ & $1,60 \%$ & $83,01 \%$ & B \\
\hline Conector Barra/Pino & $13.603,35$ & $1,57 \%$ & $84,58 \%$ & B \\
\hline Gancho DTT & $11.988,55$ & $1,38 \%$ & $85,96 \%$ & B \\
\hline Pinça Bipolar & $11.006,00$ & $1,27 \%$ & $87,22 \%$ & $\mathrm{~B}$ \\
\hline Haste Transversal & $10.031,54$ & $1,15 \%$ & $88,38 \%$ & $B$ \\
\hline Parafuso Cânulado Titânio & $9.757,43$ & $1,12 \%$ & $89,50 \%$ & B \\
\hline Parafuso Esponjoso & $9.691,76$ & $1,12 \%$ & $90,62 \%$ & B \\
\hline Conjunto para Vertebroplastia & $8.960,00$ & $1,03 \%$ & $91,65 \%$ & B \\
\hline Cimento Ortopédico & $8.022,40$ & $0,92 \%$ & $92,57 \%$ & B \\
\hline $\begin{array}{l}\text { Cateter de drenagem externa de Líquido } \\
\text { Cefalorraquidiano (LCR) }\end{array}$ & $7.903,47$ & $0,91 \%$ & $93,48 \%$ & B \\
\hline Parafuso Cânulado Inox & $7.590,63$ & $0,87 \%$ & $94,36 \%$ & B \\
\hline Splint Nasal & $6.556,94$ & $0,75 \%$ & $95,11 \%$ & C \\
\hline Tunnel Button & $6.380,00$ & $0,73 \%$ & $95,85 \%$ & C \\
\hline Parafuso de Interferência & $6.012,85$ & $0,69 \%$ & $96,54 \%$ & C \\
\hline
\end{tabular}




\begin{tabular}{|c|c|c|c|c|c|}
\hline Parafuso Tampão & $\mathrm{R} \$$ & $4.985,50$ & $0,57 \%$ & $97,11 \%$ & C \\
\hline Fresa Cirúrgica & $\mathrm{R} \$$ & $4.560,00$ & $0,53 \%$ & $97,64 \%$ & C \\
\hline Pino de Schanz & $\mathrm{R} \$$ & $4.193,54$ & $0,48 \%$ & $98,12 \%$ & C \\
\hline Conjunto para Irrigação & $\mathrm{R} \$$ & $3.899,00$ & $0,45 \%$ & $98,57 \%$ & C \\
\hline Placa para Clavícula & $\mathrm{R} \$$ & $3.850,89$ & $0,44 \%$ & $99,01 \%$ & C \\
\hline Capa Protetora para Itens & $\mathrm{R} \$$ & $1.726,74$ & $0,20 \%$ & $99,21 \%$ & C \\
\hline Arruela Inox & $\mathrm{R} \$$ & $1.638,21$ & $0,19 \%$ & $99,40 \%$ & C \\
\hline Fio de Kirschner & $\mathrm{R} \$$ & $1.388,01$ & $0,16 \%$ & $99,56 \%$ & C \\
\hline Fio Guia & $\mathrm{R} \$$ & $1.318,47$ & $0,15 \%$ & $99,87 \%$ & C \\
\hline Caneta para Marcação Cirúrgica & $\mathrm{R} \$$ & 681,00 & $0,08 \%$ & $99,94 \%$ & C \\
\hline Arruela Titânio & $\mathrm{R} \$$ & 518,44 & $0,06 \%$ & $100,00 \%$ & C \\
\hline Total & $\mathbf{R} \mathbf{S}$ & $8.536,77$ & $100 \%$ & - & - \\
\hline
\end{tabular}

A curva $A B C$ mostrou quais os produtos que mais influenciam no faturamento e que devem receber maior atenção pela empresa. Do mesmo modo, essa curva mostrou os produtos que menos interferiram no faturamento e que devem receber uma atenção mais reduzida se comparados aqueles que mais influenciam na receita da empresa.

A ferramenta de gestão de estoque, denominada de curva $A B C$, indica a redução de esforços em determinados produtos e mostra em quais produtos esses esforços devem ser redirecionados. Assim, ela permite identificar os produtos que podem ser colocados em promoções para aumentar o giro e faturamento, bem como mostrar quais produtos devem ter sua reposição mais eficientemente planejada.

Considerando que a empresa analisada ainda não utiliza ferramentas de gestão de estoque e realiza a manutenção das quantidades de materiais de acordo com a experiência e senso comum, foi calculado o consumo médio, a variação do consumo (desvio padrão), leadtime, estoque de segurança, lote econômico de compra, ponto de pedido e estoque máximo. Tais dados estão disponíveis no quadro 3.

Quadro 3: Resultados das ferramentas de gestão.

\begin{tabular}{|c|c|c|c|c|c|c|c|}
\hline Produto & \begin{tabular}{|l} 
Média \\
Mensal
\end{tabular} & \begin{tabular}{|l|} 
Desvio \\
Padrão
\end{tabular} & $\begin{array}{l}\text { Leadtime } \\
\text { (Mensal) }\end{array}$ & \begin{tabular}{|l|} 
Estoque de \\
Segurança
\end{tabular} & LEC & $\begin{array}{l}\text { Estoque } \\
\text { Máximo }\end{array}$ & $\begin{array}{l}\text { Ponto de } \\
\text { Pedido }\end{array}$ \\
\hline Adesivo Cirúrgico & 3 & 1,17 & 0,4 & 2 & 10 & 12 & 4 \\
\hline Arruela Inox & 3 & 2,25 & 0,6 & 2 & 10 & 12 & 4 \\
\hline Arruela Titânio & 1 & 0,98 & 0,75 & 1 & 5 & 6 & 2 \\
\hline Barra Tubular & 8 & 5,57 & 0,75 & 6 & 16 & 22 & 12 \\
\hline Botão de fechamento de crânio & 1 & 2,45 & 0,25 & 1 & 5 & 6 & 2 \\
\hline Broca Craniana & 4 & 1,03 & 0,4 & 2 & 11 & 13 & 4 \\
\hline Cage Cervical & 2 & 0,98 & 0,6 & 2 & 8 & 10 & 4 \\
\hline Campo Cirúrgico & 3 & 1,76 & 0,35 & 2 & 10 & 12 & 4 \\
\hline Caneta para Marcação Cirúrgica & 1 & 0,52 & 0,35 & 1 & 5 & 6 & 2 \\
\hline Cânula para Artroscopia & 3 & 3,16 & 0,4 & 2 & 10 & 12 & 4 \\
\hline Capa Protetora para Itens & 3 & 5,21 & 0,45 & 2 & 10 & 12 & 4 \\
\hline $\begin{array}{l}\text { Cateter de drenagem externa de } \\
\text { Líquido Cefalorraquidiano (LCR) }\end{array}$ & 1 & 1,26 & 0,6 & 1 & 5 & 6 & 2 \\
\hline Cimento Ortopédico & 3 & 2,73 & 0,4 & 2 & 10 & 12 & 4 \\
\hline Clip Intracraniano & 1 & 0,82 & 1 & 1 & 5 & 6 & 2 \\
\hline Compressa Neurocirúrgica & 10 & 4,62 & 0,8 & 8 & 18 & 26 & 16 \\
\hline Conector Barra/Pino & 17 & 13,66 & 0,75 & 13 & 24 & 37 & 26 \\
\hline Conjunto para Irrigação & 2 & 1,51 & 0,6 & 2 & 8 & 10 & 4 \\
\hline Conjunto para Vertebroplastia & 1 & 0,84 & 0,4 & 1 & 5 & 6 & 2 \\
\hline Contra parafuso com anel & 34 & 21,2 & 0,25 & 9 & 34 & 43 & 18 \\
\hline Fio de Kirschner & 3 & 2,94 & 0,6 & 2 & 10 & 12 & 4 \\
\hline Fio Guia & 2 & 1,86 & 0,6 & 2 & 8 & 10 & 4 \\
\hline Fresa Cirúrgica & 2 & 1,51 & 0,4 & 1 & 8 & 9 & 2 \\
\hline Gancho DTT & 4 & 4,13 & 0,25 & 1 & 11 & 12 & 2 \\
\hline Haste Longitudinal & 13 & 6,43 & 0,25 & 4 & 21 & 25 & 8 \\
\hline Haste Proximal & 1 & 1,21 & 0,75 & 1 & 5 & 6 & 2 \\
\hline
\end{tabular}




\begin{tabular}{|l|l|l|l|l|l|l|l|} 
Haste Transversal & 3 & 2,4 & 0,25 & 1 & 10 & 11 \\
\hline Hemostático & 13 & 4,04 & 0,6 & 8 & 2 \\
\hline Hidroxiapatita & 4 & 1,86 & 0,4 & 2 & 29 & 16 \\
\hline Membrana Sintética & 2 & 1,55 & 0,4 & 1 & 11 & 13 & 4 \\
\hline Parafuso Auto compressivo & 1 & 0,41 & 0,6 & 1 & 8 & 9 & 2 \\
\hline Parafuso Cânulado Inox & 3 & 2,32 & 0,75 & 3 & 5 & 6 & 2 \\
\hline Parafuso Cânulado Titânio & 2 & 1,47 & 0,75 & 2 & 10 & 13 & 6 \\
\hline Parafuso Cortical Inox & 22 & 14,82 & 0,75 & 17 & 8 & 10 & 4 \\
\hline Parafuso Cortical Titânio & 14 & 11,06 & 0,75 & 11 & 27 & 44 & 34 \\
\hline Parafuso de Bloqueio Inox & 5 & 3,73 & 0,75 & 4 & 22 & 33 & 22 \\
\hline Parafuso de Interferência & 1 & 0,75 & 0,75 & 1 & 13 & 17 & 8 \\
\hline Parafuso Esponjoso & 5 & 4,5 & 0,75 & 4 & 5 & 6 & 2 \\
\hline Parafuso Monocortical & 7 & 3,61 & 0,75 & 6 & 13 & 17 & 8 \\
\hline Parafuso Pedicular Poliaxial & 34 & 20,81 & 0,25 & 9 & 15 & 21 & 12 \\
\hline Parafuso Tampão & 1 & 1,1 & 0,75 & 1 & 34 & 43 & 18 \\
\hline Pinça Bipolar & 1 & 0,89 & 0,4 & 1 & 6 & 2 \\
\hline Pino de Schanz & 10 & 8,04 & 0,75 & 8 & 5 & 6 & 2 \\
\hline Placa para Cervical & 3 & 1,17 & 0,4 & 2 & 18 & 26 & 16 \\
\hline Placa para Clavícula & 1 & 0,55 & 0,75 & 1 & 10 & 12 & 4 \\
\hline Placa Tubular & 2 & 1,22 & 0,75 & 2 & 5 & 6 & 2 \\
\hline Splint Nasal & 2 & 0,98 & 0,4 & 1 & 8 & 10 & 4 \\
\hline Tunnel Button & 1 & 0,82 & 0,75 & 1 & 8 & 9 & 2 \\
\hline Válvula para Hidrocefalia & 5 & 2,73 & 0,4 & 2 & 5 & 6 & 2 \\
\hline
\end{tabular}

Inicialmente foi mensurado o estoque de segurança, através do produto do consumo médio e do leadtime. Esta ferramenta apresenta a quantidade de materiais que devem permanecer em estoque para diminuir as probabilidades de falta e não fornecimento do serviço. Vale ressaltar a necessidade de ter uma gestão de estoque adequada para a empresa analisada, pois como ela atende procedimentos cirúrgicos de urgência, emergência e eletiva, a ausência de um material pode interferir na saúde do paciente e até levá-lo a óbito.

Considerando os custos de pedido, armazenamento e demanda média dos materiais comercializados pela empresa, calculou-se o lote econômico de compra (LEC). Essa ferramenta permite identificar a quantidade ideal de material que pode ser comprada, de forma que os custos do pedido e de armazenamento sejam minimizados. O LEC permite que os produtos sejam comprados com uma frequência menor, mas em quantidades maiores. Com isso, além de otimizar os custos de pedido e armazenamento, pode diminuir os custos com fretes e aumentar o poder de barganha da empresa em relação a seus fornecedores com uma possibilidade maior de obter descontos.

À medida que ocorrem as cirurgias, os níveis de estoque da empresa são reduzidos. Para garantir que não chegue a uma quantidade inferior à necessária até que as novas aquisições cheguem, é importante um momento adequado para realizar o pedido. Dessa forma, calculou-se o Ponto de Pedido (PP), a partir do produto do consumo médio e leadtime, e posteriormente adicionado o estoque de segurança. O PP é uma medida preventiva para oscilações na demanda e faz com que a empresa otimize seu fluxo de caixa. A partir do momento que o estoque da empresa decresce e atinge determinada quantidade, inicia-se o processo de reposição, considerando o consumo ininterrupto até essa reposição chegar.

Materiais odonto-médico-hospitalares possuem alto custo de aquisição e podem interferir nos fluxos de caixa da empresa. Ter estoques elevados como forma de diminuir o risco de falta de materiais, pode ser nocivo para a empresa. Dessa forma, foi mensurado o estoque máximo, através da soma do estoque de 
segurança e lote econômico de compra. O estoque máximo permite estabelecer um limite para a quantidade de materiais em estoque, como forma de diminuir o impacto financeiro.

Em entrevista com o gestor, foi relatado que a não utilizava as ferramentas de gestão de estoque apresentadas neste estudo, devido a pouco atenção dada ao setor de materiais. Outro ponto relevante da entrevista foi o desconhecimento que a expansão do mix de produtos estava trazendo problemas para a organização, devido à ausência de giro de mais da metade dos novos produtos.

Além dos recursos financeiros demandados para aquisição, existe o custo de oportunidade, depreciação, vencimento de material, danos que inviabilizam a comercialização e o custo de obsolescência. Com a evolução dos procedimentos de saúde, produtos são substituídos por outros constantemente, gerando necessidade de inovação constante. Assim, são necessários recursos financeiros para reinvestimento da empresa, através de pesquisa e desenvolvimento (P\&D). Com estoques elevados, o dinheiro que poderia estar sendo utilizado para fins de P\&D acaba estagnado no estoque, devido a diferentes níveis de liquidez e giro.

\section{CONCLUSÕES}

O objetivo do presente estudo foi analisar e propor um plano de gerenciamento de estoques em uma empresa de fornecimento de materiais odonto-médico-hospitalares na cidade de Vitória da Conquista - BA. A partir dos dados e informações coletadas, é possível afirmar que a empresa não estava realizando uma gestão eficiente dos estoques com base no senso comum. As ferramentas de gestão aplicadas neste estudo têm como objetivo melhorar a eficiência operacional e financeira da organização analisada.

Com um mercado cada vez mais competitivo, qualquer ferramenta que contribua para a eficiência e competitividade é válida. Gerir estoques antes vistos como algo sem relevância, vem ganhando espaço e atenção dentro das organizações, pois o estoque de materiais é responsável pela continuidade das operações na maioria das empresas. Além de afetar as atividades operacionais, também interfere na saúde financeira, melhorando a liquidez e diminuindo os custos de oportunidade.

A principal contribuição deste estudo é voltada para a área gerencial com implicações práticas, a partir da aplicação de ferramentas de gestão de estoque como estoque mínimo, estoque máximo, lote econômico de compra, ponto de pedido e curva $A B C$. A utilização dessas ferramentas podem ser aplicadas em qualquer organização, de maneira a se proteger contra falta de materiais, evitar compras equivocadas, perda de vendas e interrupção das atividades operacionais.

Uma limitação do presente estudo está relacionada a não generalização dos resultados, pois a pesquisa foi realizada em uma empresa específica, a qual possui particularidades. Outra limitação é que as equações utilizadas no presente estudo são simples, com pouca robustez e não devem ser utilizadas arbitrariamente sem considerar as características das organizações e o segmento de atuação.

Para futuras pesquisas, sugere-se que sejam utilizadas outras equações mais robustas e previstas na literatura para os cálculos dos mesmos indicadores utilizados na presente pesquisa. Além disso, utilizar outras ferramentas de gestão de estoque, bem como elaborar as próprias ferramentas a fim de contribuir 
para literatura sobre gestão de suprimentos. Outra sugestão é realizar uma revisão sistemática da literatura para verificar quais os avanços que as ferramentas de gestão de estoque estão implicando para as organizações, bem como quais são as principais ferramentas utilizadas.

\section{REFERÊNCIAS}

ARNOLD, J. R. T.. Administração de materiais: uma introdução. São Paulo: Atlas, 1999.

CALACIO, R. A. B.; SOUZA, V. L.; LOOSE, C. E.; OLIVEIRA, N. D. A.; ALEIXO, A. D.. Gestão de Estoques em Empresas Supermercadistas do Município de Cacoal, Estado de Rondônia. Revista Eletrônica Organizações e Sociedade, Iturama, v.9, n.11, p.5-26, 2020

CORRÊA, H. L.; GIANESI, I. G. N.; CAON, M.. Planejamento, programação e controle da produção: MRP II/ERP: conceitos, uso e implantação base para, Oracle Applications e outros softwares integrados de gestão. 5 ed. São Paulo: Atlas, 2007.

DANDARO, F.; MARTELLO L. L.. Planejamento e Controle de Estoque nas Organizações. Revista Gestão Industrial, Ponta Grossa, v.11, n.2, p.170-185, 2015. DOI: http://doi.org/10.3895/gi.v11n2.2733

DIAS, M. A. P.. Administração de materiais: princípios, conceitos e gestão. 5 ed. São Paulo: Atlas, 2010.

DIAS, M. A. P.. Administração de materiais: princípios, conceitos e gestão. 6 ed. São Paulo: Atlas, 2012.

GIL, A. C.. Como elaborar projetos de pesquisa. 6 ed. São Paulo: Atlas, 2017.

KLIPPEL, M.; ANTUNES JÚNIOR, J. A. V.; VACCARO, G. L. R.. Matriz de posicionamento estratégico de materiais: conceito, método e estudo de caso. Gestão \& Produção, v.14, n.1, p.181-192, 2007. DOI: http://dx.doi.org/10.1590/s0104-530x2007000100015

LEITE, P. R.. Logística reversa: meio ambiente e competitividade. São Paulo: Pearson Prentice Hall, 2005.
MOREIRA, D. A.. Administração da produção e operações. São Paulo: Saraiva, 2012.

OLIVEIRA, C. M.; CARVALHO, M. F. H.. Análise de Políticas de Gestão em Cadeias de Suprimentos por Modelos de Simulação. Gestão e Produção, São Carlos, v.11, n.3, p.313329, 2004.

OLIVEIRA, É. D.; MICHALSKI FILHO, C.. Lote Econômico de Compra: Uma ferramenta para a eficiente gestão de aquisição de materiais. In: CONGRESSO INTERNACIONAL DE ADMINISTRAÇÃO - ADM. Anais. Ponta Grossa, 2015.

PAOLESCHI, B.. Estoques e armazenagem. São Paulo: Érica, 2014.

PERES, S. R.; RABELO, J. C.; FURQUIM, M. G. D.; SOUZA JÚNIOR, J. C.. Avaliação de implantação da ferramenta de controle de estoques curva abc em uma empresa de produtos agropecuário. Revista Brasileira de Administração Científica, v.11, n.3, p.144-154, 2020. DOI: http://doi.org/10.6008/CBPC2179-684X.2020.003.0010

POZO, H.. Administração de recursos materiais e patrimoniais: uma abordagem logística. 7 ed. São Paulo: Atlas, 2015.

ROSA, H.; MAYERLE, S. F.; GONÇALVES, M. B.. Controle de estoque por revisão contínua e revisão periódica: uma análise comparativa utilizando simulação. Production, v.20, n.4, p.626-638, 2010. DOI: http://dx.doi.org/10.1590/s010365132010005000052

SLACK, N.; BRANDON-JONES, A.; JOHNSTON, R.. Administração da produção. 8 ed. São Paulo: Atlas, 2018.

WILD, T.. Best practice in inventory management. Oxford: Elsevier, 2002

A CBPC - Companhia Brasileira de Produção Científica (CNPJ: 11.221.422/0001-03) detém os direitos materiais desta publicação. Os direitos referem-se à publicação do trabalho em qualquer parte do mundo, incluindo os direitos às renovações, expansões e disseminações da contribuição, bem como outros direitos subsidiários. Todos os trabalhos publicados eletronicamente poderão posteriormente ser publicados em coletâneas impressas sob coordenação da Sustenere Publishing, da Companhia Brasileira de Produção Científica e seus parceiros autorizados. Os (as) autores (as) preservam os direitos autorais, mas não têm permissão para a publicação da contribuição em outro meio, impresso ou digital, em português ou em tradução. 